FINANCIAL: Jurnal Akuntansi

Published by Program Studi Akuntansi STIE Sultan Agung

Volume 6-Nomor 1, Juni 2020, (Hlm 1-16)

ISSN-P: 2502-4574, ISSN-E: 2686-2581

Available online at: https://financial.ac.id/index.php/financial

\title{
ANALISIS FISHBONE DIAGRAM UNTUK MENGEVALUASI PROSES BISNIS DISTRIBUSI AIR PADA PDAM STUDI KASUS PADA PDAM TIRTA RAYA KABUPATEN KUBU RAYA
}

\author{
Djunita Permata Indah \\ Program Studi Akuntansi, Universitas Tanjungpura, Pontianak, Kalimantan Barat, Indonesia. \\ E-mail: Djunitapermataindah@ekonomi.untan.ac.id
}

\begin{abstract}
Abstrak
Penelitian ini bertujuan untuk mengevaluasi proses bisnis distribusi air pada PDAM Tirta Raya Kabupaten Kubu Raya. Penyelenggaraan pelayanan air minum yang efektif dan efisien menjadi sangat penting dalam pengelolaan bagi PDAM. Salah satu Penyebab terjadinya proses bisnis yang tidak efektif dan efisien di PDAM Tirta Raya adalah adanya tingkat kebocoran yang tinggi. Sehingga perlu dilakukan evaluasi terkait proses pendistribusian air oleh PDAM Tirta Raya dan mencari faktor-faktor apa saja yang menyebabkan kebocoran atau NRW yang terjadi sangat tinggi. Alat ukur yang digunakan berupa fishbone diagram untuk mencari penyebab dari nilai kebocoran atau NRW yang terjadi. Penelitian ini menggunakan jenis penelitian kualitatif dengan model pendekatan studi kasus di PDAM Tirta Raya Kabupaten Kubu Raya. Pengumpulan data dilakukan dengan terjun langsung ke lapangan, melihat, mengobservasi, mengumpulkan data primer dengan melakukan wawancara secara langsung. . Penyebab terjadinya tingkat kehilangan air berasal dari beberapa faktor seperti kurangnya ketelitian dan koordinasi di PDAM Tirta Raya di bagian instalasi dan perusahaan. Selain itu pada jalur pendistribusian masih terdapat banyak kebocoran pipa yang menyebabkan nilai NRW yang cukup tinggi dan water meter pelanggan yang telah rusak menyebabkan penggunaan air tidak tercatat. Sedangkan pada tingkat pengolahan umur mesin yang sudah tua dan telah aus, spesifikasi dan kelengkapan alat ukur yang ada di instalasi tidak ada.
\end{abstract}

Kata kunci: Fishbone, efektif, efisien, dan PDAM.

\section{FISHBONE DIAGRAM ANALYSIS TO EVALUATE WATER DISTRIBUTION FROM BUSINESS PROCESS IN PDAM CASE STUDY IN PDAM TIRTA RAYA KUBU RAYA DISTRICT}

\begin{abstract}
This study aims to evaluate the business process of water distribution in PDAM Tirta Raya, Kubu Raya Regency. Providing effective and efficient drinking water services is very important in the management of PDAMs. One of the causes of ineffective and inefficient business processes in PDAM Tirta Raya is the high level of leakage known as Non Revenue Water. So it needs to be evaluated related to the process of water distribution by PDAM Tirta Raya and look for any factors that cause leakage or NRW that occurs very high. Measuring instruments used in the form of fishbone diagrams to find the cause of the value of leakage or NRW that occurs. This research uses qualitative research with a case study approach model in PDAM Tirta Raya, Kubu Raya Regency. Data collection is done by going directly into the field, seeing, observing, collecting primary data by conducting interviews in person. . The cause of the high level of water loss comes from several factors such as lack of accuracy and coordination in PDAM Tirta Raya in the installation department and the company. In addition, in the distribution channel there are still many pipe leaks which cause high NRW values and customer water meters that have been damaged causing unused water usage. Whereas at the processing level the age of the machine is old and has worn out, the specifications and completeness of the existing measuring instruments at the installation do not exist.
\end{abstract}

Keywords: Fishbone, effective, efficient, and PDAM.

Article History: Received: 15 Apr 2020 Revised: 18 Mei 2020 Accepted: 28 Mei 2020 


\section{PENDAHULUAN}

PDAM menempati posisi yang unik dalam ekonomi lokal, yaitu memonopoli pasar penyediaan air bagi masyarakat umum dengan harga yang terjangkau, dan dituntut untuk berdiri sendiri membiayai operasionalnya. Dalam hal ini, tuntutan terhadap penyelenggaraan pelayanan air minum yang efektif dan efisien menjadi sangat penting sesuai dengan mandat pada Peraturan Pemerintah Nomor 122 Tahun 2015. Namun, data menunjukkan sebagian PDAM di wilayah Indonesia memiliki masalah dalam pelayanan dan operasionalnya guna mencapai mutu pelayanan 3K (kualitas, kuantitas, dan kontinuitas) dan masih mengalami kesulitan untuk mencapai laba dari penjualan air.

Executive Summary buku kinerja PDAM 2016 menyatakan bahwa salah satu parameter penyebab utama kinerja PDAM tidak sehat adalah adanya tingkat kehilangan air yang tinggi. Terhitung hanya ada 39 PDAM dari total 371 PDAM yang tingkat non-revenue water (NRW) atau air takberekening di bawah 20\%. Non-revenue water (NRW) atau air tak berekening yang juga dikenal dengan kehilangan air merupakan masalah utama yang mempengaruhi permintaan manajemen air perkotaan bagi negara berkembang, termasuk di dalamnya adalah Indonesia.

Global World WATER Forum II di Den Haag tahun 2000 memprediksi pada tahun 2025 Indonesia juga dapat mengalami krisis air akibat dari kesalahan pengelolaan air. Secara nasional, Indonesia bersama Thailand, Vietnam, Laos dan Malaysia memiliki rata-rata NRW sebesar 35\%. Dari 402 pelayanan air publik milik pemerintah dan swasta $75 \%$ berada pada tingkatan operasional buruk karena NRW yang tinggi. Namun, pada tahun 1997, Manila berhasil melakukan pengurangan NRW yang signifikan dari $70 \%$ ke $11 \%$ (Baietti, William,\& Meike, 2006; Rivera, 2014). Di tahun yang sama, indonesia masih mencatat kebocoran di beberapa daerah hingga 3050\% (Ararl, Eduardo dan Wang, 2013). Hal ini juga tergambarkan dari laporan manajemen PDAM Tirta Raya dimana total NRW pada tahun 2013 hingga 2016 pada Tabel 1.1

Tabel 1.1 Tingkat NRW PDAM Tirta Raya Kabupaten Kubu Raya Periode 2013-2016

\begin{tabular}{|c|c|c|c|c|}
\hline & 2013 & 2014 & 2015 & 2016 \\
\hline Produksi $\left(\mathbf{m}^{3}\right)$ & $2,894,380$ & $2,996,605$ & $2,801,401$ & $3,297,528$ \\
\hline Distribusi $\left(\mathbf{m}^{3}\right)$ & $2,239,804$ & $2,355,669$ & $2,669,502$ & $2,637,894$ \\
\hline Terjual $\left(\mathbf{m}^{3}\right)$ & $1,378,010$ & $1,670,725$ & $1,801,685$ & $1,714,142$ \\
\hline $\begin{array}{l}\text { NRW Produksi } \\
(\%)\end{array}$ & $22.62 \%$ & $21.39 \%$ & $4.71 \%$ & $20.00 \%$ \\
\hline $\begin{array}{l}\text { NRW Distribusi } \\
(\%)\end{array}$ & $38.48 \%$ & $29.08 \%$ & $32.29 \%$ & $35.02 \%$ \\
\hline Total NRW & $61.10 \%$ & $50.47 \%$ & $37.00 \%$ & $55.02 \%$ \\
\hline
\end{tabular}

Sumber: Laporan Manajemen

Berdasarkan Tabel 1.1 di atas dapat dilihat bahwa nilai NRW di tahun 2013 sampai dengan tahun 2016 sangat fluktuatif bahkan sampai pada angka tertinggi $61,10 \%$. Artinya dari proses produksi, distribusi, hingga penagihan tidak beroperasi dengan optimal.

Rumusan masalah dalam penelitian ini berfokus pada mengevaluasi proses bisnis pada PDAM Tirta Raya Kabupaten Kubu Raya. Salah satu Penyebab terjadinya proses bisnis yang tidak efektif dan efisien di PDAM Tirta Raya adalah adanya tingkat kebocoran yang tinggi. Oleh sebab itu diperlukan alat ukur yang dapat mengetahui akar penyebab masalah yang timbul saat ini. Alat ukur yang akan digunakan pada penelitian ini adalah diagram sebab-akibat atau fishbone diagram. 


\section{LANDASAN TEORI}

\section{Pengertian Proses Produksi}

Menurut Assauri dalam Jani (2014), proses produksi merupakan suatu kegiatan yang menggunakan semua faktor produksi dalam rangka menciptakan sebuah barang agar memiliki nilai guna ataupun menambah dari nilai guna barang tersebut. "Proses produksi merupakan cara, metode, dan teknik untuk menciptakan atau menambah dari kegunaan suatu barang atau jasa dengan menggunakan sumber-sumber seperti tenaga kerja, mesin, bahan-bahan dan dana yang ada. Terdapat dua jenis proses produksi yaitu:

1. Proses produksi yang terus-menerus (continuous processes) memiliki sifat atau ciri-ciri berupa:

a. Hasil produksi yang berjumlah besar (produksi massal) dengan variasi yang sangat kecil dan sudah terstandarisasi.

b. Proses menggunakan sistem atau cara penyusunan perakatan berdasarkan pengerjaan dari produk yang dihasilkan

c. Mesin yang digunakan selama proses produksi merupakan mesin yang bersifat khusus.

d. Pengaruh individual operator terhadap produk yang dihasilkan kecil sekali, sehingga operator tidak perlu memiliki skill atau keahlian yang tinggi untuk pengerjaan produk tersebut.

e. Bila salah satu mesin/peralatan terhenti atau rusak, maka seluruh proses produksi akan terhenti

f. Mesin-mesin bersifat khusus dan variasi dari produknya kecil, maka job structure juga sedikit dan jumlah tenaga kerjanya tidak perlu banyak.

g. Persediaan bahan mentah dan bahan dalam proses lebih rendah dari intermittent process/ manufacturing.

$\mathrm{h}$. Diperlukan maintenance specialist yang mempunyai pengetahuan dan pengalaman yang banyak.

Copyright (C) 2020, FINANCIAL: Jurnal Akuntansi i. Bahan-bahan dipindahkan dengan peralatan handling yang bersifat tetap (fixed path equipment).

2. Proses produksi yang terputus-putus (intermittent process)

a. Produk yang dihasilkan dalam jumlah sangat kecil dengan variasi yang sangat besar (berbeda) dan didasarkan pada pesanan

b. Menggunakan sistem atau cara penyusunan peralatan berdasarkan atas fungsi dalam proses produksi atau peralatan yang sama dikelompokkan pada tempat yang sama (process lay out atau departmentation by equipment)

c. Mesin yang dipakai bersifat umum, yang dapat menghasilkan bermacam-macam produk dengan variasi yang hampir sama (general purpose machines)

d. Akibat mesin yang bersifat umum dan biasanya kurang otomatis, maka diperlukan operator yang memiliki keahlian atau skill yang tinggi dalam pengerjaannya.

e. Proses produksi tidak mudah terhenti, walaupun kerusakan akibat terhentinya salah satu mesin atau peralatan.

f. Akibat mesin-mesin yang bersifat umum dan variasi produk yang besar, maka pekerjaan (job) yang bermacam-macam menimbulkan pengawasan yang lebih sulit.

g. Biasanya bahan-bahan dipindahkan dengan peralatan handling yang bersifat fleksibel (flexible) atau varied path equipment yang menggunakan tenaga manusia seperti kereta dorong atau forklift.

h. Selama proses pemindahan bahan yang bolak-balik, diperlukan adanya ruang gerak (aisle) yang cukup besar dan ruangan tempat bahan-bahan dalam proses (work in process) yang besar. 


\section{Proses Bisnis}

Perusahaan tentunya akan fokus dalam memberikan barang atau jasa kepada pelanggan dengan cara yang paling efisien. Mengontrol kinerja proses bisnis secara konstan penting bagi perusahaan guna meningkatkan dan memperbarui kegiatan serta pengelolaan sumber daya perusahaan. Optimalisasi dari proses bisnis sendiri penting bagi perusahaan guna keberlanjutan dari proses bisnis dimana perbaikan secara berkelanjutan dari proses bisnis dapat mengurangi biaya, waktu dan sumber daya lainnya yang dimiliki oleh perusahaan. Termasuk juga didalamnya meningkatkan kualitas bisnis (Pusnik,et al, 2020).

Bakotic dan Ante (2017) merangkum definisi dari proses bisnis sebagai sebuah proses yang komprehensif, rangkaian aktivitas yang berkoordinasi secara dinamik atau tugas-tugas yang terhubung secara logis yang harus diselesaikan untuk memberikan nilai kepada pelanggan atau untuk memenuhi tujuan strategis lainnya. Dua anteseden terkait manajemen proses bisnis berasal dari Walter A. Shewhart dan W. Edwards Deming yang berfokus pada kontrol proses statistik yang kemudian kita ketahui sebagai gerakan kualitas modern "Six Sigma". Dimana konsep ini berusaha untuk mengurangi dari variasi kinerja pekerjaan dengan secara hati-hati mengukur hasil dan menggunakan teknik statistik untuk mengisolasi "akar penyebab" dari masalah kinerja. Proses sendiri didefinisikan sebagai sebuah dasar dari setiap urutan kegiatan kerja. Definisi lain dari proses bisnis yaitu suatu pekerjaan end-to-end di perusahaan yang menciptakan nilai bagi pelanggan (Hammer, 2010).

\section{Fishbone Diagram}

Penggunaan fishbone diagram lekat kaitannya dengan pengendalian mutu atau kualitas. Sebagai contoh, Xerox menggunakan diagram fishbone untuk fokus identifikasi penyebab dan menstrukturkan akar penyebab masalah dari masalah kualitas yang mereka hadapi (Rao, et al., 1996). Mendeteksi masalah yang dimiliki dalam proses bisnis yang perusahaan miliki sangat penting guna mengatasi secara cepat masalah utama yang dimiliki perusahaan selama melakukan proses bisnis. Secara alami, adanya cacat pada jalur produksi dapat menyebabkan kerugian baik secara material, waktu, dan uang yang cukup signifikan (Horev, 2008).

Menurut Besterfield (2004) diagram sebab-akibat atau fishbone diagram merupakan sebuah gabungan garis dan simbol yang menunjukkan hubungan sebab dan akibat.

Liliana (2016) merangkup empat langkah penggunaan fishbone diagram:

1. Identifikasi masalah

2. Mencari tahu faktor-faktor utama yang terlibat

3. Mengidentifikasi kemungkinan penyebab

4. Menganalisis diagram

Sebab dari permasalahan yang dialami selama proses bisnis biasanya dikelompokkan ke dalam kategori utama untuk mengidentifikasi sumber-sumber variasi penyebab masalah, kategori-kategori tersebut diantaranya (Bose, 2012; Liliana, 2016; Hilton, 2008):

1. People atau manusia, merupakan sumber daya manusia yang terlibat dengan proses bisnis perusahaan. Personel yang memiliki kompetensi sesuai dengan yang dituntut oleh pekerjaannya akan memiliki kemampuan untuk menerapkan pengetahuannya ke dalam pekerjaan, sehingga menjanjikan produktivitas dalam menghasilkan produk/jasa dan 
cost effectiveness dalam pemanfaatan sumber daya.

2. Methods atau metode, merupakan cara atau bagaimana proses bisnis dilakukan dan ketentuan atau persyaratan khusus untuk melakukan sesuatu, baik itu kebijakan, prosedur, aturan, peraturan, dan hukum.

3. Machines atau mesin, merupakan segala bentuk peralatan, komputer, alat, dan lainnya yang diperlukan selama proses bisnis berlangsung untuk menyelesaikan pekerjaan.

4. Materials atau bahan, merupakan bahanbahan yang diperlukan selama proses produksi, seperti bahan baku, suku cadang, pena, kertas, dan lainnya yang digunakan untuk menghasilkan produk akhir.

5. Measurement atau pengukuran, merupakan data yang dihasilkan dari proses yang digunakan untuk mengevaluasi kualitas barang atau jasa.

6. Environment atau lingkungan, merupakan kondisi seperti lokasi, waktu, suhu, maupun budaya dimana suatu proses beroperasi. Dalam hal ini adalah perusahaan dan proses bisnisnya.

\section{METODE}

Penelitian ini menggunakan jenis penelitian kualitatif dengan model pendekatan studi kasus di PDAM Tirta Raya Kabupaten Kubu Raya. Pengumpulan data dilakukan dengan terjun langsung ke lapangan, melihat, mengobservasi, mengumpulkan data primer dengan melakukan wawancara secara langsung. Selanjutnya peneliti melakukan interpretasi data dengan mengidentifikasi proses bisnis di PDAM Tirta Raya dan menghubungkannya dengan komponen dari fishbone diagram.

Copyright (C) 2020, FINANCIAL: Jurnal Akuntansi

\section{HASIL DAN PEMBAHASAN Proses Produksi PDAM Tirta Raya}

Berdasarkan hasil observasi yang dilakukan dari tanggal 25 September - 28 Oktober 2017, alur proses kegiatan operasional pelayanan air di PDAM Tirta Raya dimulai dengan proses penyediaan air melalui beberapa tahap yang cukup panjang.

1. Pemompaan Air Baku

Pemompaan air baku merupakan tahapan pertama dalam sistem penyediaan air. Tahapan ini dimulai dengan pemompaan air baku yang berasal dari aliran Sungai Kapuas melalui intake atau bangunan penangkap/penyadap air baku yang bersumber dari air permukaan sungai. Dalam persiapan pemompaan air baku, petugas di IKK terkait diwajibkan untuk melakukan pemeliharaan rutin untuk mengecek bahwa air yang diambil merupakan air permukaan sungai dan tidak ikut menyedot lumpur maupun benda-benda yang tergenang pada aliran sungai Kapuas

2. Unit Transmisi

Air baku yang sudah dipompa kemudian dialirkan ke jaringan pipa menuju Instalasi Pengolahan Air (IPA). Pada IKK per wilayah cakupan PDAM Tirta Raya, seluruh pengaliran air menggunakan bantuan tenaga pompa. Air baku yang sudah dipompa kemudian dialirkan ke IPA kemudian akan dilakukan penampungan air .Para petugas IKK memiliki kewajiban untuk melakukan pemeliharaan rutin maupun berkala seperti memastikan bagaimana kondisi fisik pipa transmisi air baku, membersihkan jalur pipa transmisi dari sampah, kotoran, memperbaiki atau mengganti komponen pada jalur pipa transmisi, hingga memperbaiki 
kebocoran ataupun mengecat bangunan dan sarana penunjang lain guna menghindari korosi dan kerusakan lainnya.

3. Unit Produksi

IPA merupakan bangunan pengolahan air bersih yang berfungsi sebagai unit produksi di setiap Instalasi milik PDAM Tirta Raya. Unit produksi merupakan sarana dan prasarana yang dapat digunakan untuk mengolah air baku menjadi air bersih melalui proses fisik, kimiawi dan/atau biologi. Setelah air baku diambil, akan dilanjutkan dengan mengirim air tersebut ke WTP (Water Treatment Plant) yang merupakan bangunan utama untuk pengolahan air bersih. Air baku kemudian dipompa ke bak koagulasi untuk dilakukan proses pencampuran bahan kimia (koagulan) dengan air baku. Hal ini bertujuan untuk membentuk flok (gumpalan lumpur) pada proses koagulasi. Setelah itu air akan masuk ke unit flokulasi, dimana air dan partikel flok terpisah dengan memanfaatkan proses endapan secara gravitasi dan masuk ke proses sedimentasi untuk mengalirkan air yang telah bersih dari flok dan kemudian dilakukan filtrasi pada unit filtrasi untuk menyaring dengan media berbutir seperti pasir khusus hingga akhirnya air ditampung ke reservoir dan kemudian didistribusikan dengan bantuan pompa pendorong pada masing-masing wilayah pelayanan.

\section{Proses Bisnis PDAM Tirta Raya}

Bagi PDAM Tirta Raya pelayanan penyediaan air kepada pelanggan, merupakan inti dari bisnis PDAM. Visi dan misi yang diemban oleh PDAM Tirta Raya. Dalam memberikan pelayanan air, PDAM diharapkan untuk memenuhi 4K (Kualitas,
Kuantitas, Kontinuitas, dan Keterjangkauan harga air). Namun penelitian ini hanya akan berfokus pada $3 \mathrm{~K}$ pertama (Kualitas, Kuantitas, dan Kontinuitas). Selama proses penyediaan layanan air, terdapat beberapa kendala yang dapat dijabarkan sebagai berikut:

1. Kualitas

Kualitas air yang harus diproduksi oleh PDAM harus memiliki karakteristik seperti keadaan fisik, kimiawi dan biologis yang telah diatur lebih lanjut oleh Peraturan Menteri Kesehatan Nomor 492/Menkes/Per/IV/2010. Sedangkan untuk persyaratan kualitas air bersih yang dapat digunakan untuk keperluan sehari-hari adalah air yang memenuhi syarat kesehatan dan dapat diminum apabila telah dimasak. Hasil penelitian menemukan bahwa pdam Tirta Raya saat ini hanya mampu memberikan standar $\mathrm{pH}$ pada kisaran angka 5 hingga 7. Angka ini menjadi patokan kelayakan air karena air baku yang diperoleh merupakan air permukaan sungai dengan $\mathrm{pH}$ yang mudah terpengaruh oleh keadaan cuaca.

"setau saya tuh misalkan air yang jadi (layak didistribusikan) tuh $\mathrm{pH}$ nya 7.”(R5)

"Jadi gini, kite nih di pontianak, dan sekitarnya kubu raya beda dengan jawa, disanakan air gravitasi, kalau disinikan air sungai. Kalau misal hari ujan air bise kotor, nah itu kadang-kadang nak sampaikan angka 7 pun harus banyak nambahkan ini itu. Angka 7 tuh normal, sebenarnya dibawah, kayak 5 atau 6 itu jadi (layak didistribusikan) sebenarnye, cuma standarnya 7.”(R5)

Permasalahan lain yang timbul adalah alat-alat pengujian yang pernah ada saat ini telah rusak. Sehingga terjadi kedala 
dalam pengujian kualitas air, termasuk pengujian $\mathrm{pH}$.

“...Pertame, fasilitas ndak ade. Lab ndak ade, alat jar test ndak ade,..,",(R1) "...dulu tuh ade lab, dulu tuh ade ruangan lab tuh disamping ruang pompa distribusi. Yang disebrang lapangan bulu tangkis. Itu lah sebenarnya ruang lab. Tapi banyaklah hal gelas pecah, kite nak ngadekan (tes air), ndak ade duet.” (R1)

Berdasarkan observasi yang telah dilakukan pada tanggal 23 Oktober 2017 di IKK Desa Kapur, selama proses produksi air berlangsung hal pertama yang dapat dilihat ialah warna air baku yang masih coklat, kemudian diproses hingga air menjadi jernih. Ketika kondisi air pada bak sedimentasi masih terlihat flok yang tidak mengendap, maka diperlukan backwash, yaitu kondisi dimana operator harus membuang air yang berada pada bagian filter. Hal ini dilakukan guna menjaga bak filtrasi tetap bersih sehingga flok dapat mengendap dan kualitas air yang sampai ke pelanggan sudah tidak terdapat jumlah flok yang banyak bahkan tidak ada.

\section{Kuantitas}

Kuantitas yang perlu dicapai untuk pelayanan air oleh PDAM merupakan jumlah air yang harus tersedia berdasarkan pemakaian rata-rata untuk pelanggan rumah tangga. Pemakaian ini diatur dalam Peraturan Menteri Dalam Negeri Nomor 71 Tahun 2016 dengan kebutuhan Rumah Tangga (RT) per bulan berkisar $10 \mathrm{~m}^{3}$. Hingga tahun 2016, tercatat bahwa pemakaian rata-rata Rumah Tangga di wilayah cakupan PDAM Tirta Raya adalah sebesar 9,16 kubik/bulan dan pemakaian rata-rata keseluruhan pelanggan sebesar 9,60 kubik/ bulan.

Berdasarkan aspek kuantitas, pemakaian rata-rata yang tercatat masih kurang dari peraturan yang berlaku. Hal ini disebabkan oleh kondisi rusaknya water meter dari sebagian besar pelanggan, sehingga pemakaian air yang tercatat sebesar 0 (nol) $\mathrm{m}^{3}$. Kondisi water meter pelanggan yang tercatat $0 \mathrm{~m}^{3}$ dapat dikatakan bahwa para pelanggan tidak menggunakan air yang dialirkan oleh PDAM. Namun pada kenyataannya, bisa saja air sudah digunakan, namun PDAM tidak dapat menagih jumlah tersebut akibat tidak terdapat bukti jelas akibat tidak terekam pada water meter pelanggan ataupun akibat penyalahgunaan distribusi khusus seperti MBR (Masyarakat Bawah Rata-Rata).

"Masalah kebocoran, itu tadi, banyak pelanggan itu yang ilegal. Artinya tidak ada, 3000-4000 rumah yang tidak ada water meter artinya itu ilegal, dipasang mereka, air mengalir, itu kan kebocoran yang sangat mistis mereka pakai seenak udel mereka, tidak ada water meter, bayar 50 ribu, kalau ade water meter kan bise 150 ribu, 200 ribu kan, ini lah pemain ilegal”(R7)

“...yang kedua, ade namenye MBR masyarakat bawah rate-rate, mereke dikenakan cuma gratis biaye pasang, bulanan kite ndak gratiskan. Sebenarnya ndak bagus juga karne manjakan orang, orang ni udah dikasi gratis, berbagi pula. Ade juga yang disalahgunakan, yang mampu malah dapat MBR (Masyarakat Bawah Rata-Rata)”(R1) 


\section{Kontinuitas}

Berdasarkan Peraturan Kementerian Pekerjaan Umum Nomor 18 Tahun 2007 menyebutkan bahwa pelayanan SPAM harus memiliki pelayanan secara penuh 24 jam per hari. Namun, di PDAM Tirta raya, hingga tahun 2016 air yang dapat didistribusikan hanya berkisar 16.60 jam per hari saja. Penyebabnya adalah mesin pompa transmisi dan distribusi yang sudah tua dan rusak, pipa transmisi/ distribusi rusak dan sering terjadinya pemadaman listrik (PLN).

“...Misal dinamo terbakar...”(R1)

"beberapa kali mati lampu, perbaikan pompa"(R1)

“...selama bise dipake jalan terus, cumakan kite ade 2 pompa, pompa 1 rusak, pompa satunya dipakai. Gitu $l a$ die."(R1)

\section{Analisis Fishbone Diagram (Diagram Sebab dan Akibat)}

Berdasarkan hasil observasi dan wawancara yang peneliti lakukan, alur proses kegiatan operasional pelayanan air di PDAM Tirta Raya memiliki beberapa masalah. Mencari penyebab dari masalah yang yang dihadapi oleh PDAM Tirta Raya dapat diidentifikasi dengan melakukan analisis sebab akibat atau lebih dikenal dengan fishbone diagram dengan menelusuri proses bisnis dan melakukan justifikasi.

Beberapa unsur dari proses bisnis pada PDAM Tirta Raya dapat dilihat melalui Gambar.1, dengan fokus pada empat masalah besar yang dihadapi oleh PDAM Tirta Raya diantaranya:

1. Manusia

a. Ketelitian

Faktor pertama adalah para petugas di bagian instalasi masih kurang teliti dan Copyright (C) 2020, FINANCIAL: Jurnal Akuntansi melakukan sistem operasional sesuai standar kebiasaan. Bukan sesuai standar yang seharusnya. Hal ini juga terjadi pada proses penerimaan bahan kimia dan bahan pembantu. Pegawai yang berada di instalasi pengolahan air tidak melakukan tugasnya secara teliti sehingga terkadang terdapat masalah terkait jumlah bahan kimia dan bahan pembantu yang datang ternyata tidak sesuai dengan yang dipesan. Hal ini disebabkan oleh tidak adanya pemeriksaan ketika barang datang akibat rasa percaya kepada pemasok. Namun, walaupun perusahaan telah mengetahui hal tersebut belum dilakukan tindakan guna mencegah hal tersebut terjadi kembali.

“...dari dulu dah ndak pernah ditimbang” (R1)

"Standarnya harusnya cuma 18 biase (digunakan). Tibe-tibe 2 bulan berturut-turut 20, 21. Kan bingung, ngape pula banyak benar dengan kapasitas dan debit air yang same. Malah harusnya lebih kecil” (R1)

\section{b. Keterampilan}

Keterampilan teknis dan teoretis pegawai PDAM Tirta Raya dapat didorong dengan pendidikan dan pelatihan sesuai dengan bidangnya ( $s k i l l$ ). Masalah pertama yang di hadapi untuk sumber daya manusia di PDAM Tirta Raya juga berawal dari proses perekrutan pegawai. Semenjak tahun 2013 perusahaan terus melakukan penambahan karyawan dari 74 pegawai menjadi 89 pegawai di tahun 2016. Selama empat tahun terakhir, komposisi pendidikan yang paling banyak adalah lulusan SMA/K diikuti dengan Strata 1, Diploma dan SMP. Hal ini terjadi karena selama ini pengangkatan pegawai tidak menggunakan regulasi, dalam hal ini perda, yang berlaku. 
Sehingga perusahaan perlu melakukan pelatihan dan pembinaan kepada para pegawai agar mereka memiliki skill dan kemampuan yang sesuai dengan tanggung jawab mereka saat ini. Namun adanya keterbatasan menyebabkan perusahaan harus memilah-milah siapa saja yang dapat mengikuti pelatihan. Selain itu, rolling atau mutasi pegawai yang tidak sesuai bidangnya dapat menghambat peningkatan kompetensi pegawai. Sehingga pegawai tidak dapat secara maksimal membantu dalam meningkatkan produktivitas bagi perusahaan.

"pelatihan tuh sebenarnya ade 2 tempat. Pelatihan ini kita pilih-pilih juga, ade pelatihan yang tidak dipungut biaya dan yang dipungut biaya. Kayak misalnya pelatihan ke Bekasi, itu semua ditanggung semua, cuma kita beli tiket, nanti disana di ganti. Kalau pelatihan kite tuh kirim (karyawan). Kalau di kota Pontianak ini bayarkan, sekarang agik gencar-gencarnya kita kirimkan, cuma dengan kemampuan kita, kita pilih-pilihlah, jadi emang ndak semua bisa. Pilih-pilih aja"(R5,)

"die nih biase gini, kayak kemaren contohnya pak GH (inisial), dulu kan di bagian umum kemudian pindah lagi ke instalasi, dari bagian umum ke umum jadi ke instalasi. Makenye gajinya tuh keliatan naik turun-naik turun, soalnya ade mutasi" (R2)

\section{c. Koordinasi}

Selama proses observasi yang dilakukan oleh peneliti juga mendapati adanya kurangnya koordinasi antar bagian perusahaan (internal) dan eksternal, dalam hal ini dengan Pemda Kubu Raya. Meningkatkan kesadaran, ketelitian dan koordinasi kepada para pegawai dan eksternal agar dapat bekerja lebih efektif

Copyright (C) 2020, FINANCIAL: Jurnal Akuntansi dan efisien guna menghindari pemborosan yang terjadi akibat sangat diperlukan jika perusahaan ingin meningkatkan mutu pelayanan yang baik guna memenuhi sasaran mutu $3 \mathrm{~K}$.

"Pipa proyek masuk tidak pernah koordinasi dengan kite. Pipa induk (pipa pengantar air) tuh masuk gila-gilaan, tapi ndak ade ngelapor ke kite. Kayak yang di parit bugis, kan udah ade (pipa) 150 kan, nah nak nambah agik pipa 100 disebelahnye. Kan mubazir. Itu kita ndak diberi tahu"

\section{Material}

a. Air Baku

Proses penyediaan air bersih dimulai dari proses pengambilan air baku yang berasal dari aliran sungai kapuas yang mengalir panjang. Pengamatan observasi pertama kali di IKK Desa Kapur menunjukkan kondisi air baku sendiri cukup berlumpur dan sering kali ditemui sampah dan plastik yang mengapung.

Kondisi ini dapat mengancam kondisi pompa dan pipa yang digunakan untuk menyedot air ke pengolahan. Sumber air baku yang ini juga memiliki masalah tambahan ketika musim kemarau tiba, selain debit air yang berkurang dan mulai masuknya air laut ke dalam aliran sungai yang menyebabkan air sungai menjadi payau (air tawar yang bercampur dengan air asin). Lumpur dan air payau ini memberikan efek pompa yang digunakan oleh PDAM mudah aus. Kondisi air baku yang digunakan oleh PDAM Tirta Raya harus selalu diperhatikan oleh para operator di lapangan guna menghindari penyebab seperti sampah dan lumpur ikut masuk selama proses penyedotan air baku agar 
tidak merusak mesin pompa dan mengendap pada jaringan pipa transmisi.

"Pompa tuh terutame kalau misalnya aek sungai kapuas surut, otomatiskan aek dari laut masuk. Masuk ke pompa, ndak kuat jadinye pompa narek aer dari laot (sungai) tu. Air asin. Makenye cepat makan pompe die (aus) cepat merusak"(R2).

\section{b. Bahan Kimia}

Bahan kimia yang saat ini digunakan oleh PDAM Tirta Raya adalah tawas. Penggunaan tawas telah memiliki standarnya sendiri yaitu sebanyak 375 kilogram per 8 jam dengan estimasi sebanyak 8 karung yang seharusnya berjumlah 400 kilogram. Namun PDAM Tirta Raya sering menghadapi masalah berupa timbangan tawas yang datang ternyata tidak memiliki jumlah berat yang sama dan menimbulkan selisih yang cukup tinggi antara yang dipesan dan yang datang. Sehingga perusahaan dapat melakukan peninjauan kembali terhadap pemasok bahan kimia guna menghindari kesalahan tersebut.

"Oh kalau dari kapan aku ndak tau tuh jun. soalnya dari dulu dulu dah, dari dulu dah ndak pernah ditimbang." (RI)

"Standarnya harusnya cuma 18 biase (digunakan). Tibe-tibe 2 bulan berturutturut 20, 21, Kan bingung, ngape pula banyak benar dengan kapasitas dan debit air yang same. Malah harusnya lebih kecil karne beberapa kali mati lampu, perbaikan pompa. Jadi isenglah dicek, ternyate didapatlah seperti itu hasilnya (timbangan). Kemaren terakher, tige kali terakher (di tahun
2017) sempat pesan 5000, yang datang, pokoknya selisih 256kg lah.” (RI)

c. Pipa

Dalam Peraturan Daerah Kabupaten Kubu Raya Nomor 5 Tahun 2011 pada tanggal 18 April 2011. PDAM Tirta Raya Kabupaten Kubu Raya memiliki kewajiban untuk menyediakan air minum bagi masyarakat di daerah dan juga pengelolaan air agar dapat menunjang pembangunan ekonomi daerah. Bidang usaha penyediaan air minum diharapkan dapat dilakukan melalui perpipaan, yang sehat, dan memenuhi syarat bagi masyarakat di daerah Kabupaten Kubu Raya. Sayangnya masih sering terjadi keluhan oleh pelanggan terkait air yang mengalir ke rumah mereka dalam keadaan yang tidak layak. Hal ini disebabkan akibat kondisi pipa yang kotor akibat tidak dilakukannya proses pembuangan air guna membersihkan pipa dari endapan lumpur yang ada akibat kurangnya anggaran yang dimiliki.

"kite ngarapkan harus ade buangan air. Cuma rate-rate malah dijadikan sambungan baru, tak kuase nak nebok. Yang kite harapkan kan konsumen buang aek biar berseh. Nah tapi konsumen ngamok la, bawa contoh aek itam, ye kite bilang lah ade yang bocor. Padahal emang pipanye yang kotor....Hm betaon taon dah ndak pernah dibersihkan. Karne itu, kalau dulu kenapa ndak dibersihkan anggaran terlalu besar"(R1)

3. Mesin

a. Umur/Kondisi Mesin

Mesin yang dimiliki oleh PDAM Tirta Raya saat ini sudah tua. Sehingga beberapa mesin tua yang saat ini masih digunakan 
sudah memiliki kemampuan kerja yang cukup jauh dari yang seharusnya. Namun pemerintah daerah telah membantu PDAM dengan memberikan mesin baru. Sayangnya untuk mesin baru yang diberikan oleh pemda tidak sesuai spesifikasi yang sesuai dengan kondisi di lapangan. Seperti mesin pompa yang memiliki tegangan yang lebih tinggi ataupun memiliki kekuatan dorong yang lebih tinggi menyebabkan lumpur yang mengendap pada jaringan pipa distribusi ikut terdorong hingga sampai ke pelanggan. Hal ini harus dilakukan agar dapat melakukan penilaian dan pertimbangan terhadap mesin yang telah tua maupun yang baru agar aset mesin tidak menganggur dan dapat digunakan dengan maksimal.

"(umur mesin) udah 4-6 tahun da. Maintenance kalau udah rusak jak. Misal dinamo terbakar, atau karetnye rusak. Itu jak, sisanye ndak ade maintenance.”(R1)

"karenakan gini, kenapa pdam itu banyak tinggi kebocoran, pertama karena pipa, pompa, udah pada umur puluhan tahun, jadi kebocoran tinggi”(R7)

\section{b. Spesifikasi}

Imbas dari koordinasi yang tidak baik antara pihak perusahaan (internal) dan pihak pemda (eksternal) salah satunya adalah mesin baru yang diberikan oleh pemda tidak sesuai spesifikasi dengan kondisi yang diperlukan di lapangan. Seperti mesin pompa yang memiliki tegangan yang lebih tinggi ataupun memiliki kekuatan dorong yang lebih tinggi menyebabkan lumpur yang mengendap pada jaringan pipa distribusi ikut terdorong hingga sampai ke pelanggan. Mesin yang tidak sesuai spesifikas ini pernah membakar gardu dan menyebabkan produksi terhambat.

"kadang gitulah orang kantor tuh. Kite keluhkan ini, tadak dibelikannye. Masalah belanje, kadang yang beli ndak tau spesifikasi yang dibutuhkan,.....kayak kemarin aku cerite, (pompa) di kapur karne listrik ndak ngangkat (daya rendah) itu putaran tinggi."'(R1)

\section{c. Kelengkapan alat}

Meteran induk sebagai alat pengukur jumlah air yang disedot dan diproduksi oleh PDAM Tirta Raya tidak secara merata dimiliki pada setiap instalasi. Hal ini menyebabkan perusahaan tidak dapat secara akurat menilai berapa banyak jumlah yang diproduksi secara jelas. Selama ini para operator atau pegawai di instalasi pengolahan hanya menghitung berdasarkan perkiraan kekuatan mesin pompa. Sedangkan pada mesin pompa yang sudah tua tidak memiliki kemampuan yang sama seperti dahulu. Memiliki meteran induk menjadi penting bagi perusahaan agar perusahaan dapat memiliki jumlah produksi dan distribusi air yang akurat guna menghindari tercatatnya kehilangan air secara administratif.

"meteran induk dibeberapa tempat ade. Ade sebenarnya meter induk, tapi ndak tau barangnye kemane. Karne dulukan dicabutlah ape. Dari awal pembuatan pdam, seluruhnya tuh udah ade sетие" $(\mathrm{R} 1)$ 


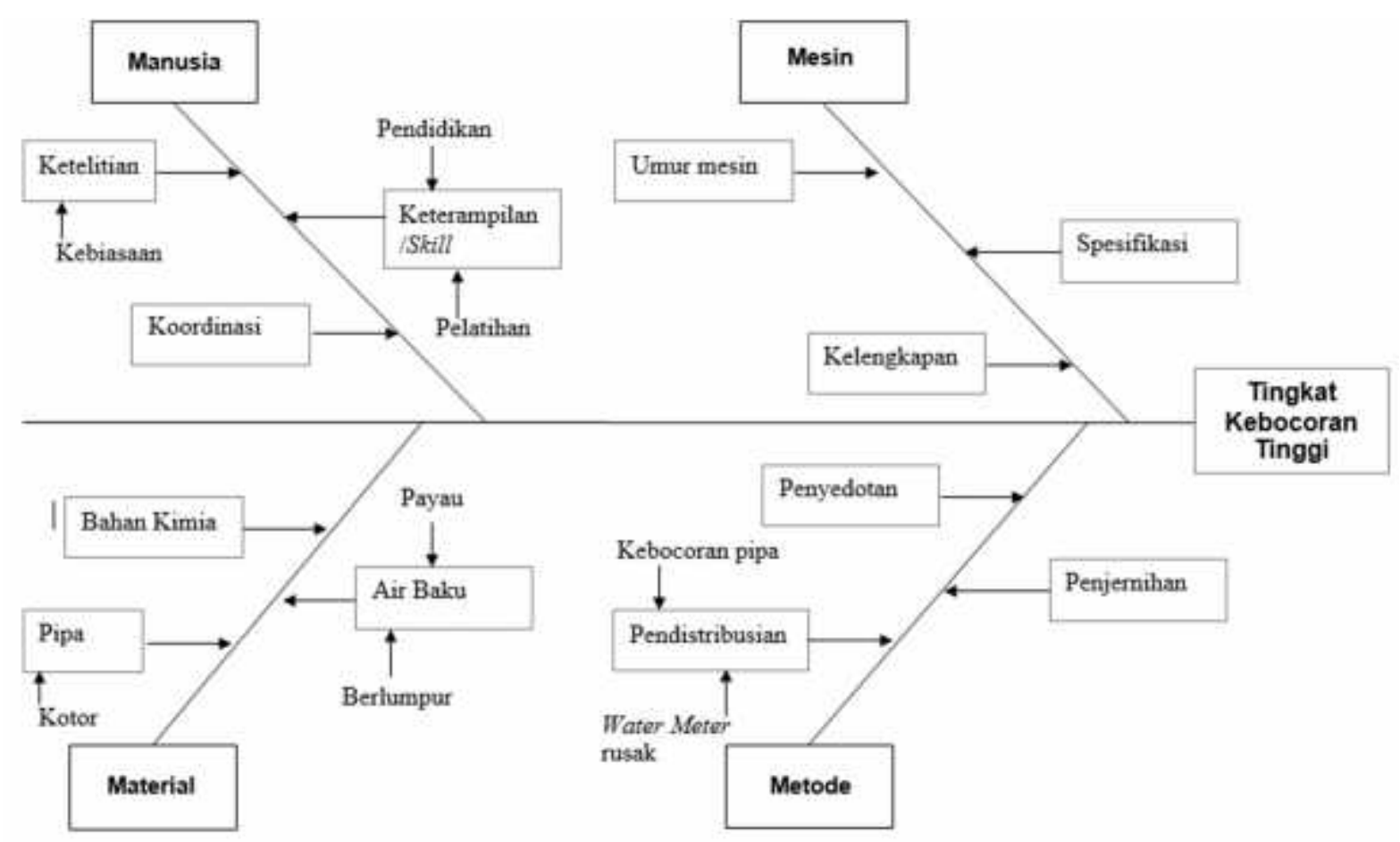

Gambar 1. Fishbone diagram PDAM Tirta Raya

Sumber: diolah, 2018

\section{Metode}

a. Penyedotan

Proses penyedotan berada pada unit pemompaan air baku. Pegawai yang bertanggung jawab pada proses ini disebut Pegawai Sumber. Masalah yang muncul pada proses ini adalah Pegawai sumber memiliki tanggung jawab untuk mengawasi pemompaan air baku agar mesin tidak menyedot lumpur dan menyebabkan kerusakan mesin pompa. Telaah dokumen menunjukkan bahwa beban pegawai sumber tidak selalu ada, hanya muncul pada tahun 2014 saja. Artinya tidak terdapat orang yang melakukan proses pengawasan pada tahap ini. Padahal pada proses penyedotan ini diperlukan pengawasan dan pemeliharaan intake (bangunan yang berisi mesin penyedot air baku). Berdasarkan hasil observasi pada tanggal 27 September 2017 di Instalasi Utama dan tanggal 23 Oktober 2017 di IKK Desa Kapur memang tidak

Copyright (C) 2020, FINANCIAL: Jurnal Akuntansi terlihat adanya Pegawai Sumber. Sehingga yang mengawasi proses ini adalah Operator Pengolahan (Pegawai di bagian Intalasi).

b. Penjernihan

Proses penjernihan dilakukan pada bagian Instalasi Pengolahan. Hal yang perlu dilakukan pada proses ini adalah melakukan pemeliharaan rutin dan pemeliharaan berkala. Pemeliharaan rutin diantaranya ialah melakukan pengecekan terkait kebersihan sampah di sekitar bar screen (penahan benda besar seperti plastik, kayu, dan sampah), membersihkan lumpur di sekitar sungai dekat intake, mengecek kondisi pompa, genset dan kontrol panel, hingga mengecek bangunan sipil umum dari kerusakan struktur bangunan. Sedangkan pemeliharaan berkala seperti memelihara pompa, genset, dan kontrol panel secara berkala, mengecek dan mengecat bangunan sipil umum bila diperlukan guna menghindari peralatan dan perlengkapan yang terbuat dari logam tidak berkarat.

Tugas pegawai instalasi pengolahan terkait pengolahan air dari persiapan, 
pengoperasian, pengawasan dan pelaporan. Selama proses persiapan operator diharuskan mengatur debit air yang akan diproduksi/diolah, menentukan stroke (prosentase bukaan pompa agar bahan kimia yang dinjeksikan sesuai dengan keinginan) pompa pembubuh bahan kimia/pembubuhan secara gravitasi, mempersiapkan larutan bahan kimia hingga melakukan pra kondisi (peninjauan ulang) jika terdapat kondisi yang tidak sesuai. Hal ini diungkapkan seperti hasil wawancara berikut ini:

"Iye (pengawasan proses), proses pengolahan air dari die nyedot, sampai air dorong ke booster. Nanti di booster ade agik operator yang bertugas untuk ngisi booster same pendorong kalau udah penoh. Gitu die.”(R1,)

Sedangkan selama proses pengoperasian sudah merupakan proses pengaliran air dengan kekuatan gravitasi dan bantuan pendorong pompa pada masing-masing proses dari koagulasi hingga penampungan air hasil olahan. Operator kemudian mengawasi tingkat kekeruhan air hasil sedimentasi dan filtrasi. Pada tahap ini operator diwajibkan melakukan pengawasan terkait kualitas air seperti mengukur $\mathrm{pH}$ air hasil olahan, mengukur kekeruhan air hasil olahan dan mengamati gejala gangguan proses pengendapan. Sayangnya, pada proses ini operator hanya mampu melakukan pengecekan berdasarkan kondisi fisik air saja seperti tingkat kekeruhan ataupun kondisi flok yang ada. Selain itu juga akibat kebiasaan hanya melakukan pemeriksaan seperti yang selama ini dilakukan, membuat operator tidak mengikuti standar operasional prosedur yang ada.

"Backwash itu airnya dibuang, supaya air endapan yang keruh tidak mengganggu proses produksi air....kalau posisinya kayak gini (flok masih banyak pada posisi permukaan air). Kalau kayak gini ndak (flok terlihat mulai mengendap). Kan karne jarak pompa aer (dari disedot ke pengolahan) jadi bercampur udara. Jadi ade gelembung air, pengaruhnya endapan/kotoran naik." (R1)

"kalo menurut sop itu 1 shift 2x tapi nyatenye kalo aek udah bersih kan sayang, mubazir kalau bersih kite backwash... kalau udah keroh benar barulah dibackwash" (R1)

"Kalo menurut skemanye, harusnya ade. Setiap shift itu 2 orang. Per 8 jam ade 2 orang. Empat jam per orang harusnyekan. Disitu per 4 jam dicek airnye gimane kondisinya, kondisi aek sungai macam mane. Kondisi aek di reservoar macam mane, air di pengolahan macam mane, flok-nye naek ke ndak, harusnya dicek semue. Ah tapi kenyataanye pade nganggap biasenye kayak gini, kebiasaan seperti ini, (jadi) ndak pernah dikerjakan (sesuai SOP)"(R1)

\section{c. Pendistribusian}

Proses pendistribusian di PDAM Tirta Raya diawasi oleh pegawai instalasi transmisi/distribusi memiliki tugas untuk mengawasi seluruh jaringan perpipaan yang dimiliki oleh PDAM baik itu mengalirkan air baku ke pengolahan hingga mengalirkan air ke pelanggan. Pada proses pengoperasian, pemeriksaan pada pipa transmisi air baku dan pipa distribusi harus dilakukan untuk memeriksa jalur pipa terhadap adanya kebocoran/ kerusakan. Selain itu, untuk pipa transmisi/distribusi, para pegawai instalasi transmisi/distribusi harus memeriksa jalur adanya rembesan air dan retakan pada 
bangunan air yang menandakan adanya kebocoran.

Secara umum, pegawai instalasi transmisi/distribusi diwajibkan untuk melakukan persiapan, mengidentifikasi kondisi tekanan air, membaca data tekanan air, mengoperasikan katup pengatur aliran apabila tidak sesuai dengan rencana, mengawasi tekanan air dan melakukan pelaporan. Pegawai juga diharuskan mengumpulkan informasi dan laporan dari petugas jaringan distribusi dan hublang (hubungan langganan) tentang zona-zona atau daerah pelayanan yang tidak mendapatkan pengaliran air atau tekanan air yang rendah. Jika terjadi kebocoran, maka tanggung jawab berada pada pegawai instalasi transmisi/distribusi untuk segera menindak laporan terkait kebocoran yang masuk.

Masalah lain yang terjadi selama proses pendistribusian air adalah banyaknya water meter pelanggan yang rusak. Sehingga PDAM Tirta Khatulistiwa kesulitan dalam menagih air yang telah terdistribusikan namun tidak dapat ditagih ke pelanggan akibat mesin water meter yang rusak.

"Jadi nanti (siapapun) nulis di buku pengaduan, nanti die diteruskan ke siape, die nyatat jak....biasenye kite data, ditulis jak. Disitu kite data, kite teruskan laporan ke bagian transmisi" (R6,)

"Masalah kebocoran, itu tadi, banyak pelanggan itu yang ilegal. Artinya tidak ada, 3000-4000 rumah yang tidak ada water meter artinya itu ilegal, dipasang mereka, air mengalir, itu kan kebocoran yang sangat mistis mereka pakai seenak udel mereka, tidak ada water meter, bayar 50.000, kalau ade water meter kan bise 150.000, $200.000 \mathrm{kan}$, ini lah pemain ilegal."'(R7)

\section{SIMPULAN DAN SARAN}

Penyebab terjadinya tingkat kehilangan air berasal dari beberapa faktor. Faktor pertama adalah pada manusia. Masih kurangnya ketelitian dan koordinasi di PDAM Tirta. Faktor kedua yang menyebabkan adalah bahan-bahan material yang tidak ideal, seperti kondisi air bahan baku, bahan kimia yang tidak terukur secara pasti, dan pipa yang bocor. Sehingga diperlukan pengendalian yang baik terkait bahan-bahan material. Selain itu pada jalur pendistribusian masih terdapat banyak kebocoran pipa dan water meter pelanggan yang telah rusak menyebabkan penggunaan air tidak tercatat sehingga yang menyebabkan nilai NRW yang cukup tinggi. Sedangkan pada tingkat pengolahan umur mesin yang sudah tua dan telah aus, spesifikasi dan kelengkapan alat ukur yang ada di instalasi tidak ada. Sehingga proses produksi menjadi tidak efektif dan efisien.

PDAM Tirta Raya harus segera melakukan pengendalian terkait elemen manusia, material dan mesin secara ketat, serta melakukan perbaikan terhadap pipapipa yang bocor pada jalur distribusi. Hal ini dikarenakan jika perusahaan membiarkan hal ini terus terjadi, maka perusahaan akan terus mengalami kehilangan pendapatan yang tinggi akibat pengelolaan air yang tidak efisien dan efektif seperti air yang telah diolah tidak sampai ke pelanggan, namun hilang pada saat didistribusikan.

PDAM Tirta Raya perlu melakukan peninjauan kembali terhadap jaringan pipapipa distribusi yang dimiliki oleh 
perusahaan. Hal ini dilakukan untuk memetakan kembali terhadap jaringan pipa-pipa distribusi yang dimiliki oleh perusahaan agar mempermudah perusahaan dalam menyusun perencanaan pengembangan cakupan wilayah pelayanan. Dengan dilakukannya peninjauan kembali diharapkan perusahaan dapat dengan cermat menghindari masalah-masalah seperti kesalahan pemasangan jaringan pipa distribusi akibat kurangnya koordinasi baik dengan pihak internal maupun eksternal.

Perusahaan diharapkan melakukan pelatihan rutin tahunan guna meningkatkan keterampilan, kompetensi dan koordinasi antar karyawan. Hal ini bertujuan untuk meningkatkan produktivitas para pegawai guna mencapai hasil kerja yang lebih maksimal untuk perusahaan.

\section{DAFTAR PUSTAKA}

Baietti, Aldo., William Kingdom, dan Meike van Ginneken. (2006). Characteristics of Well-Performing Public Water Utilities. Water Supply \& Sanitation Working Notes, Note No.9, May 2006 : World Bank Group.

Bakotic, Danica., \& Ante Krnie. (2017). Exploring the Relationship Between Business Process Improvement and Employees' Behavior. Journal of Organizational Change Management, Vol. 30 No.7 pp. 1044-1062.

Bose, Tarun Kanti. (2012). Apllication of Fishbone Analysis for Evaluating Supply Chain and Business Process-A Case Study on The St. James Hospital. International Journal of Managing Value and Supply Chains. Vol.3, No. 2.

Hammer, Michael. (2010). Handbook on Business Process Management 1,
Introduction, Methods, and Information System. New York: Springer.

Hennik, Monique, Inge Hutter, dan Ajay Bailey. (2011). Qualitative Researh Methods. London: SAGE Publications Ltd.

Horev, Menachem. (2008). Root Cause Analysis in Process-Based Industries. Canada: Trafford Publishing.

Jani, Rahman. (2014). Analisis Pengendalian Persediaan Bahan Baku Pakan Ternak Sapi Dalam Rangka Efisiensi Dengan Menggunakan Diagram Pareto, Metode EOQ dan Diagram Sebab Akibat. Skripsi. Universitas Diponogoro.

Liliana, Luca. (2016). A New Model of Ishikawa Diagram for Quality Assessment. Materials Science and Engineering. IOP Publishing.

Malcom, Farley dkk. Disunting oleh Niels van Dijk dkk. (2008). Buku Pegangan tentang Air Tak Berekening (NRW) untuk Manajer, Panduan untuk Memahami Kehilangan Air. Ranhill, USAID, ADB, dan Direktorat Jendral Cipta Karya.

Manila Water. (2017). Manila Water 2016 integrated annual and sustainability report. Manila.

PDAM Tirta Raya. 2014. Laporan Manajemen 2013. Kabupaten Kubu Raya.

PDAM Tirta Raya. 2015. Laporan Manajemen 2014. Kabupaten Kubu Raya.

PDAM Tirta Raya. 2016. Laporan Manajemen 2015. Kabupaten Kubu Raya.

PDAM Tirta Raya. 2017. Laporan Manajemen 2016. Kabupaten Kubu Raya.

Pusnik, Maja, Tatjana Welzer Druzovec, Marjan Hericko, \& Bostjan Sumak. (2020). A Survey-Base Evaluation 
of Approaches and Tools for Business Process Optimization Support. Information Modelling and Knowledge Bases XXXI. IOS Press.

Ranganathan, C.,\& Jasbir S. Dhaliwal. (2001). A Survey of Business Process Reengineering Practices in Singapore. Information \& Management. Elsevier.

Rao, Asho., Lawrence P. Carrr, Ismael Dambolena, Robert J.Kopp, John Martin, Farshad Rafij, Phylis Fineman Schlesinger. 1996. Total Quality Management, A Cross Functional Perspective. New York, USA: John Wiley \& Son.

Republik Indonesia. 2015. Peraturan Pemerintah Nomor 122 Tahun 2015 Tentang Sistem Penyediaan Air Minum (PP SPAM).

Rivera, Virgilio C, Jr. 2014. Tap Secret, The Manila Water Story. Asian Development Bank \& Manila Water.

\section{PROFIL SINGKAT}

Djunita Permata Indah, lahir di Pontianak 14 Juni 1991. Pendidikan terakhir ditempuh di Magister Akuntansi Fakultas Ekonomika dan Bisnis Universitas Gadjah Mada, dengan konsentrasi pada bidang ilmu Akuntansi Manajemen dan lulus pada tahun 2018. Pendidikan strata 1 diselesaikan di Fakultas Ekonomi dan Bisnis Universitas Tanjungpura pada tahun 2014. Saat ini bekerja seabgai Dosen di Jurusan Akuntansi dari Fakultas Ekonomi dan Bisnis Universitas Tanjungpura 